\title{
Determination of Bioactive Chemical Composition of Zingiber Officinale Essential Oil and Investigation of Its Anti-Microbial Activity
}

\author{
Hicham Boughendjioua \\ Department of Natural Sciences, High School Professors Technological Education, Skikda, Algeria.
}

Correspondence Author: Hicham Boughendjioua. Department of Natural Sciences, High School Professors Technological Education, Skikda, Algeria. E-mail: boughendjioua.hicham@yahoo.com

Received date: 27 May 2018, Accepted date: 22 June 2018, Online date: 8 August 2018 .

Copyright: (C) 2018 Hicham Boughendjioua. This is an open-access article distributed under the terms of the Creative Commons Attribution License, which permits unrestricted use, distribution, and reproduction in any medium, provided the original author and source are credited.

\begin{abstract}
Background: Ginger is known in many countries of the world for its culinary value, but also for its therapeutic virtues, widely marketed in the Algerian markets, we are interested in its chemical composition and its biological activities. Objective: The aim of this study was to determine the chemical composition of essential oil of Zingiber officinale rhizome and evaluate their antimicrobial activity. Results: The essential oil was obtained by hydrodistillation, and the chemical composition of the oil was determined by GC-MS. It was identified 17 compounds in the essential oil, the most abundant were; Zingiberene (30.80\%), $\alpha$-Curcumene (15.80\%) and $\beta$-Sesquiphellandrene $(15.56 \%)$. To determine the antimicrobial activity diffusion, agar dilution was employed. Conclusion: The results validate the medicinal use of Zingiber officinale in the treatment of diseases of possible infectious origin.
\end{abstract}

Key words: Ginger, Zingiber officinale, essential oil, chemical composition, antimicrobial activity.

\section{INTRODUCTION}

Throughout the ages, man has been able to rely on nature to provide for his basic needs: food, shelter, clothing and also for his medical needs. The therapeutic use of the extraordinary virtues of plants for the treatment of all diseases of man is very old and evolves with the history of mankind. Still today, a majority of the world's population, especially in the developing countries development, is only treated with traditional herbal remedies. The modern pharmaceutical industry itself is still relying on the diversity of plant secondary metabolites to find new molecules with unprecedented biological properties. This source seems inexhaustible since only a small part of the 400000 known plant species have been investigated phytochemically and pharmacologically, and each species may contain up to several thousand different constituents (Hostettmann et al., 1998).

Ginger is grown in sunny and tropical areas, mainly in Asia (India, China, Nepal). There are written records of its use dating back more than 3,500 years, but it seems that its qualities have been known for more than 5,000 years. He is known in our regions thanks to the Mediterranean trade of Romans and Greeks. It is often used as a spice to decorate dishes. In Malaysia and India, where ginger comes from, it is a well-known medicinal plant, especially in Indian Ayurveda medicine which is very old. Today, it is used worldwide to treat intestinal disorders, flu-like conditions and depressed health. Ginger consists of two parts: the underground part, called the rhizome, is gnarled and branched and the aerial part is formed of leaves and a stem about one meter in height. The rhizome, whose pulp is yellow inside, serves as a reserve for the plant and ensures its survival. The leaves are alternate, lanceolate and fragrant and the flowers are yellow with a red lip. The fruits contain few black seeds. Ginger multiplies and reproduces itself rather thanks to the division of its rhizome. It needs a wet, warm and sunny weather to grow, which is why it is usually found in tropical countries. (Gingembre, http://www.doctissimo.fr/html/sante/phytotherapie/plantemedicinale/gingembre.htm).

The analysis of volatile oils from dill rhizome showed camphene, $\mathrm{p}$-cineole, $\alpha$-terpineol, zingiberene and pentadecanoic acid as major components. This oil possesses different biological properties including antibacterial, antifungal, ant-oxidative, anticancer, larvicidal, antidiabetic, anti-inflammatory and nephro/hepato-protective properties (Kumar et al., 2011).

The purpose of the present work was to determinate the chemical composition and evaluate the antimicrobial activity of Zingiber officinale essential oil marketed in Algerian markets.

Plant material:

\section{MATERIAL AND METHODS}

Ginger plant do not grow in Algeria due to weather condition. Therefore, dried rhizomes of ginger (Zingiber officinale) were purchased from the local market in Azzaba (north of Skikda, Algeria) and was identified by Dr. Hicham Boughendjioua at the Department of Natural Sciences, High School Professors Technological Education, Skikda (Algeria). 


\section{Extraction of essential oil:}

The samples were grinded, homogenized and made into a fine powder. In order to extract the essential oils, $100 \mathrm{~g}$ of the powder was placed in 01 liter conical flask and connected to the Clevenger apparatus. $500 \mathrm{~mL}$ of distilled water was added to the flask and heated to the boiling point. The steam in combination with the essential oils were distilled in to a graduated cylinder for 5 hours and then separated from aqueous layer. The oil was kept in the refrigerated until required for further analysis.

\section{GC-MS analysis of essential oil:}

The steam volatile oil from ginger was extracted and the oil was analyzed using a Shimadzu GC 2010 gas chromatograph equipped with QP 2010 mass spectrometer and RTX-5 column $(30 \mathrm{~m} \times 0.25 \mathrm{~mm}$, film thickness $0.25 \mu \mathrm{m})$. Helium was used as the carrier gas at a flow rate of $1.67 \mathrm{ml} \mathrm{min}{ }^{1}$. The injection port was maintained at $250^{\circ} \mathrm{C}$; the detector temperature was $220^{\circ} \mathrm{C}$; oven temperature was programmed as follows: $60^{\circ} \mathrm{C}$ for $5 \mathrm{~min}$ and then increased to $110^{\circ} \mathrm{C}$ at the rate of $5^{\circ} \mathrm{C}$ min- 1 , then up to $170^{\circ} \mathrm{C}$ at the rate of $3^{\circ} \mathrm{C} \mathrm{min}^{-1}$, again up to $220{ }^{\circ} \mathrm{C}$ at the rate of $5^{\circ} \mathrm{C} \mathrm{min}{ }^{-1}$, at which the column was maintained for 3 min. The split ratio was 1:40 and ionization energy $70 \mathrm{eV}$.

\section{Microbial strains:}

Microorganisms were obtained from the Bacteriology Laboratory, Faculty of Medicine, HCU of Dorban in Annaba (Algeria). Five strains of gram-negative bacteria [Escherichia coli (ATCC 25922), Klebsiella pneumoniae (ATCC 15380), Pseudomonas aeruginosa (ATCC 27853), Proteus vulgaris (MTCC 1771) and Salmonella spp. strains (Samples (date))] and three strains of gram-positive bacteria [Bacillus subtilis (MTCC 441), Staphylococcus aureus (ATCC 25923) and Listeria monocytogenes (ATCC 19112)] were used. These strains were maintained at $4^{\circ} \mathrm{C}$ in Mueller Hinton agar (Bioxon), submitted to sensitivity tests (multidiscs Bigaux) and were subcultured twice before and after bioassays.

\section{Antibacterial activity:}

The antibacterial activity of essential oil was measured by disk-diffusion method (VandenBerghe and Vlietinck, 1991). Bacterial inocula were prepared in $10 \mathrm{~mL}$ of Müller-Hinton broth (Bioxon) and incubated at $37^{\circ} \mathrm{C}$ for $24 \mathrm{~h}$. The inoculums were adjusted with sterile saline to obtain turbidity of the McFarland standard No. 0.5 (108 CFU/mL). Bacterial inocula were planted on MullerHinton agar plates. On the surface of agar, filter paper disks ( $5 \mathrm{~mm}$ diameter) impregnated with $4 \mu \mathrm{L}$ of essential oil (3.48 $\mu \mathrm{g} / \mathrm{disc})$ were placed in triplicate. As a positive control, disks impregnated with $25 \mu \mathrm{g}$ of chloramphenicol and as negative control disks with $10 \mu \mathrm{L}$ of olive oil were used. The plates were incubated at $37^{\circ} \mathrm{C}$ for $24 \mathrm{~h}$. Inhibition zones were reported in mm.

\section{Chemical composition:}

\section{RESULTS}

The essential oil is pale yellow to brown and exudes a very spicy, fresh and slightly lemony fragrance characteristic of ginger, with the following physical characteristics: Density at $20^{\circ} \mathrm{C}: 0.872$ to 0.894 , Refractive index at $20^{\circ} \mathrm{C}$ : 1.485 to 1.492 , Rotatory power at $20^{\circ} \mathrm{C}$ : $-52^{\circ}$ to $-12^{\circ}$, Flash point: $+65^{\circ} \mathrm{C}$. Zingiberene is the predominant compound belonging to the sesquiterpene hydrocarbons (the specific aroma of ginger is predominantly related to Zingiberene). The chemical constituents of the essential oil extracted as mentioned in Table $n^{\circ} 1$, where the Zingiberene is the predominant compound (Figure $\mathrm{n}^{\circ} 1$ ).

Table 1: Chemical composition and concentrations of compounds present in the Ginger essential oil.

\begin{tabular}{|c|l|c|c|}
\hline $\mathbf{N}^{\circ}$ & Compounds & RT (min) & Concentrations (\%) \\
\hline $\mathbf{0 1}$ & Camphene & 9.15 & 0.90 \\
\hline $\mathbf{0 2}$ & $\beta$-Phellandrene & 9.50 & 0.98 \\
\hline $\mathbf{0 3}$ & Endo- Borneol & 10.00 & 0.89 \\
\hline $\mathbf{0 4}$ & Geraniol & 10.87 & 0.95 \\
\hline $\mathbf{0 5}$ & Neryl acetate & 11.09 & 1.30 \\
\hline $\mathbf{0 6}$ & $\boldsymbol{\alpha}$-Curcumene & 11.89 & $\mathbf{1 5 . 8 0}$ \\
\hline $\mathbf{0 7}$ & Zingiberene & 12.99 & $\mathbf{3 0 . 8 0}$ \\
\hline $\mathbf{0 8}$ & $\alpha$-Farnesene & 14.78 & 6.00 \\
\hline $\mathbf{0 9}$ & $\beta$-Bisabolene & 15.67 & 8.98 \\
\hline $\mathbf{1 0}$ & 4, 5- Dimethy1-11-Methylene Tricycle 7 & 17.44 & 2.22 \\
\hline $\mathbf{1 1}$ & V-Cadinene & 18.98 & 3.48 \\
\hline $\mathbf{1 2}$ & $\boldsymbol{\beta}$-Sesquiphellandrene & 19.56 & $\mathbf{1 5 . 5 6}$ \\
\hline $\mathbf{1 3}$ & $\boldsymbol{\delta}$-Cadinene & 20.07 & 0.60 \\
\hline $\mathbf{1 4}$ & Nerolidol & 22.32 & 2.10 \\
\hline $\mathbf{1 5}$ & 7- $\alpha$-(1-Hydroxyl-1-Methylethyl) & 23.77 & 2.01 \\
\hline $\mathbf{1 6}$ & Germacrene B & 24.07 & 1.09 \\
\hline $\mathbf{1 7}$ & $\alpha$-Eudesmol & 25.99 & 3.27 \\
\hline
\end{tabular}




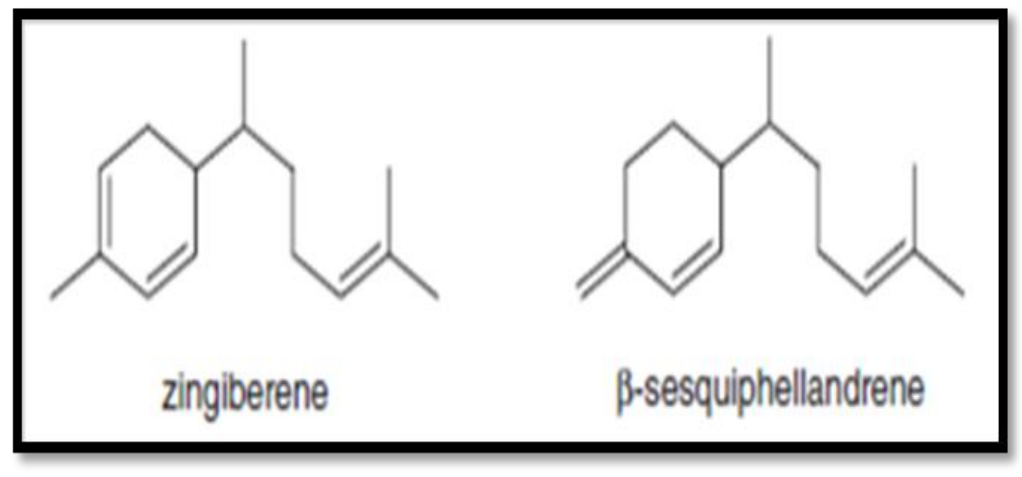

Figure 1: The major constituents of Ginger essential oil.

The chemical composition of the ginger oils (obtained by hydrodistillation) of fresh and dried rhizomes of Nigerian origin were investigated by means of a combination of column chromatography, high resolution gas chromatography (GC) and GC-MS. The essential oils contained mainly mono- and sesqui terpenoids of which geranial, neral, 1,8-cineole, zingiberene, $\beta$ bisabolene and $\beta$-sesquiphellandrene were the major components. Among the 54 constituents identified, $(E)(E)-\alpha$ farnesene, viridiflorol and (E)(E)-farnesal have not been found previously in ginger (Ekundayo et al., 1988) .

Volatile oils from two most popular cultivars from Sikkim namely, Bhaisa and Majulay, were isolated, characterised by analytical GC and GC-MS. Sixty constituents accounting for $94.9 \%$ and $92.6 \%$ of the Bhaisa and Majulay oils were identified. The major compounds of Bhaisa oil were geranyl acetate (18.8\%), zingiberene $(16.3 \%)$ and geranial $(8.2 \%)$ and those of Majulay oil were zingiberene (19.8\%) and geranial (16.5\%). Compared to other ginger cultivar oils, the Bhaisa oil had higher content of oxygenated compounds (43.1\%). This is the first report on the essential oils from Sikkim ginger cultivars (Sasidharan et al.,2011).

The chemical composition of the essential oil from the rhizome of ginger (Zingiber officinale Roscoe), collected from Nahan, Himachal Pradesh, India, was determined by gas chromatography and GC-MS. Fifty-one compounds, representing $95.1 \%$ of the oil, were identified. The oil was characterized by relatively large amounts of the monoterpenoids 1,8 -cineole (10.9\%), linalool (4.8\%), borneol (5.6\%), alpha-terpineol (3.6\%), neral (8.1\%), geraniol (14.5\%), geranial (9.5\%), trans-dimethoxy citral $(5.0 \%)$ and geranyl acetate $(6.3 \%)$. Five compounds, namely trans-linalool oxide, trans-linalool oxide acetate, (Z)-dimethoxycitral, (E)dimethoxy citral and epi-zingiberenol are reported for the first time in oil of ginger (Gupta et al., 2011). The chemical composition of the essential oil obtained from the rhizomes of Zingiber officinale Roscoe from Cuba was examined by combined GC and GC-MS. The oil was characterized by the presence of ar-curcumene (22.1\%), zingiberene (11.7\%), $\beta$-bisabolene (11.2\%) and cadina-1,4-diene (12.5\%) (Jorge et al., 2011).

The hydro-distilled essential oil of ginger (Zingiber Officinale Roscoe) rhizomes of commerce from three different geograhical locations in India, viz. Mizoram, Chennai and two varieties from Sikkim were analyzed by GC and GC-MS. In all the four oils, zingiberene $(10.5 \%-16.6 \%)$ was the major constituents and although the composition of all the oils was by and large similar, quantitative differences in the concentration of the constituents were observed. The GC and GC-MS analysis of Mizoram, Chennai and Sikkim (Majhauley and Bhainsey varieties) ginger rhizome oils resulted in the identification and quantitation of 29, 29,28 and 28 constituents representing $84.3 \%, 86.6 \%, 88.8 \%$ and $86.8 \%$ of the total oils, respectively. Among the four oils analysed the Majhauley variety had an edge over the rest of three oils due to the higher content of zingiberene (16.6\%) followed by e-citral (12.0\%), z-citral (8.8\%), camphene (7.6\%) and ocimene (6.5\%) (Raina et al., 2013).

The chemical composition of essential oils obtained by water and steam distillation of ginger from Vietnam was investigated. The yield of the essential oils was $2.05 \%$ and $2.1 \%$, respectively. The main components of the essential oil obtained by water distillation were ar-cucumene (11.7\%) and $\beta$ bisabolene (4.1\%), and of the essential oil obtained by steam distillation were arcurcumene (12.6\%), $\alpha$-zingiberene (10.3\%), $\beta$-bisabolene (8.1\%) and $\beta$-sesquiphellandrene (7.4\%) (Stoyanova et al., 2013).

This deviation from the common chemotypes may be attributed to the effect of the factors that specifically affect the composition and yield of the essential oil, which include seasonal and maturity variation, geographical origin, genetic variation, growth stages, postharvest drying and storage (Marotti et al., 1994; Hussain et al., 2008; Verma et al., 2009).

\section{Antibacterial Activity:}

Essential oil of Zingiber officinale inhibited the growth of 08 bacterial strains: five Gram-negative and three Gram-positive strains (Table 2). The range of the essential oils action against bacteria may achieve values that only inhibit the bacterial growth (bacteriostatic) or may be used at either high concentrations or are inherently more aggressive and their action results in a decline in the number of bacterial cells (bactericide). The bacteriostatic action has a reversible character since, after neutralization of the agent, the microbial cells will recover their reproductive capacity. In contrast, the bactericidal effect has a permanent effect; as even after the neutralization of the agent, the microbial cells are not capable of growth and reproduction (Bloomfield, 1991). 
Table 2: Anti-microbiological activity of the essential oil of Ginger.

\begin{tabular}{|l|c|}
\hline \multicolumn{1}{|c|}{ Strains } & Sensitivity $^{*}$ \\
\hline Escherichia coli & ++ \\
\hline Klebsiella pneumoniae & +++ \\
\hline Pseudomonas aeruginosa & ++ \\
\hline Proteus vulgaris & +++ \\
\hline Bacillus subtilis & +++ \\
\hline Staphylococcus aureus & ++ \\
\hline Listeria monocytogenes & ++ \\
\hline Salmonella & +++ \\
\hline
\end{tabular}

Each value represents the mean of two replicates \pm standard deviation

*The sensitivity to the different strains was classified by the diameter of the inhibition zone as follows (Ponce et al., 2003):

-: diameter less than $8 \mathrm{~mm}$, not sensitive;

$+:$ sensitive, diameter 9-14 mm;

++ : very sensitive, diameter $15-19 \mathrm{~mm}$;

+++ : extremely sensitive for diameter larger than $20 \mathrm{~mm}$.

All microbiological results obtained during the study shows that all the products tested have a very significant antibacterial activity, in which some strains seem to be distinguished by a very high sensitivity. Zingiberene would also include compounds providing Ginger antimicrobial properties.

Zingerone, Gingirdiol, Zingibrene, and particularly Gingerol and Shagol, Sesquiterpenes such as farnesene, corcomin and betaBisabolene are the main active ingredients of giner (Zingiber officinalae) (Giriraju and Yunus, 2013).

Auta et al., (2011) showed that ethanolic extract of ginger (Zingiber officinale) with of $20 \mathrm{mg} / \mathrm{ml}$ had stronger effect on Pseudomonas aeruginosa than Escherichia coli. Unlike, in another study water extract of ginger at the high dose (500 mg) had no antimicrobial effect on Escherichia coli, Salmonella, Shigella, and Bacillus cereus.

The antimicrobial activity of volatile oil of Zingiber Officinale Roscoe was tested against Bacillus subtilis, Staphylococcus aureus, Escherichia coli, Pseudomonas aeruginosa. The volatile oil showed significant antimicrobial activities in comparison to the standard; Tetracycline. The zones of inhibition were in the range of 10.4 to $12.5 \mathrm{~mm}$ and 8.3 to $12.5 \mathrm{~mm}$ for bacterial strains, respectively. The standard, Tetracycline had a 10.0 to $15.0 \mathrm{~mm}$ zone of inhibition. A strong antibacterial activity against Staphylococcus aureus, Pseudomonas aeruginosa followed by Escherichia coli which was on par with standard (positive control) and weaker than standard towards Bacillus subtilis. (Pradeep et al., 2016).

It has been reported that ginger (rich in sesquiterpenes) essential oils possessed a wide spectrum of antimicrobial activity (Baratta et al., 1998; Singh et al., 2008; Anwer, 2009). The obtained results corroborated with the earlier reported data of Daw et al., (1994) and Farag et al. (1989b). In general, the extract of antimicrobial mechanism of essential oils has not been completely elucidated. However, it has been proposed that the chemical structure of essential oils or their main could play an important role for the antimicrobial activity (Farag et al., 1989b; Daw et al., 1994), which may enable them to destroy the cellular structure leading to death. Therefore, the bioactivity of essential oils is dependent not only on the major compounds but also on the chemical structures of these compounds (Farag et al., 1989 b, c).

\section{CONCLUSION}

Our study has shown that Ginger essential oil (Zingiber officinale) has antibacterial properties and can therefore be used as a potential new source of natural antimicrobial. Zingiberene as a major constituent with a concentration of (30.80\%), inhibits spoilage and pathogenic bacterial growth for both Gram (+) and Gram (-), the presence of zingiberene in large amount in the essential oil makes it medicinally valuable.

\section{REFERENCES}

Anwar, F., M. Ali, A.I. Hussain and M. Shahid., 2009. Antioxidant and antimicrobial activities of essential oil and extracts of fennel (Foeniculum vulgare Mill.) seeds from Pakistan. Flavour and Fragrance Journal, 24(4): 170-176.

Auta, KI., A.A. Galadima, J.U. Bassey, O.D. Olowoniyi, O.O. Moses and A.B. Yako., 2011. Antimicrobial properties of the ethanol extracts of Zingiber officinale (Ginger) on Escherichia coli and Pseudomonas aeruginosa. Research Journal of Biological Sciences, 6(1): 37-39.

Baratta, MT., H.J. Dorman, S.G. Deans, A.C. Figueiredo, J.G. Barroso and G. Ruberto., 1998. Antimicrobial and antioxidant properties of some commercial essential oils. Flavour and Fragrance Journal, 13(4): 235-244.

Bloomfield, S.F. In: Denyer SP, Hugo WB eds. Mechanisms of action of chemical biocides. Their study and exploitation. Methods for Assessing antimicrobial activity., 1991. Technical series of the Society for Applied Bacteriology, Oxford, UK Blackwell Scientific Publications.

Daw, ZY., G.S. EL-Baroty and A.E. Mahmoud., 1994. Inhibition of Aspergillus parasiticus growth and aflatoxin production by some essential oils. Chemie Mikrobiologie Technologie der Lebensmittel, 16(5/6): 129-135. 
Ekundayo, O., I. Laakso and R. Hiltunen., 1988. Composition of ginger (Zingiber officinale roscoe) volatile oils from Nigeria. Flavour and Fragrance Journal, 3(2): 85-90.

Farag, R.S., Z. Y. Daw and S. H. Abo-Raya., 1989b. Influence of some essential oils on Aspergillus parasiticus growth and aflatoxins production in a synthetic medium. Journal of Food Science, 54: 74-67.

Farag, RS., Z.Y. Daw, F.M. Hewadi and G.S. EL-Baroty., 1989c. Antimicrobial activity of some Egyptian spice essential oils. Journal of Food Protection, 52(9): 665-667. $10 / 03 / 2018$.

Gingembre, http://www.doctissimo.fr/html/sante/phytotherapie/plante-medicinale/gingembre.htm, website accessed on

Giriraju, A. and G.Y. Yunus., 2013. Assessment of antimicrobial potential of $10 \%$ ginger extract against Streptococcus mutans, Candida albicans, and Enterococcus faecalis: an in vitro study. Indian Journal of Dental Research, 24(4): 397-400.

Gupta, S., P. Pandotra, G. Ram, R. Anand, A.P. Gupta, K. Husain, Y.S. Bedi and G.R. Mallavarapu., 2011. Composition of a monoterpenoid-rich essential oil from the rhizome of Zingiber officinale from north western Himalayas. Natural Product Communications, 6(1):93-6.

Hostettmaan, K., O. Potterat and J.L. Wolfender., 1998. The Potential of Higher Plants as a Source of New Drugs. Chimia, 52(1-2): 10-17.

Hussain, AI., F Anwar, S.T. Sherazi and R. Przybylski., 2008. Chemical composition, Antioxidant and antimicrobial activities of basil (Ocimum basilicum) essential oils depends on seasonal variations. Food Chemistry, 108(3): 986-995.

Jorge. A., R. Marbot, A. Rosado and A. Batista., 2011. Chemical Composition of the Essential Oil of Zingiber officinale Roscoe L. from Cuba. Journal of Essential Oil Research, 16(3): 186-188.

Kumar, G., L. Karthik and K.V.B. Rao., 2011. A Review on Pharmacological and Phytochemical Properties of Zingiber officinale Roscoe (Zingiberaceae). Journal of Pharmacy Research, 4(9): 2963-2966.

Marotti, M., R. Piccaglia and E. Giovanelli., 1994. Effects of variety and ontogenic stage on the essential oil composition and biological activity of fennel (Foeniculum vulgare Mill.). Journal of Essential Oil Research, 6(1): 57-62.

Ponce, AG., R. Fritz, C. Del Valle and S.I. Roura., 2003. Antimicrobial Activity of Essential Oils on the Native Microflora of Organic Swiss Chard. Lebensmittel-Wissenschaft und -Technologie, 36(7): 679-684.

Pradeep, KS., S. Vijender and A. Mohammed., 2016. Chemical Composition and Antimicrobial Activity of Fresh Rhizome Essential Oil of Zingiber Officinale Roscoe. Pharmacognosy Journal, 8(3): 185-190.

Raina, V.K., A. Kumar and K. K. Aggarwal., 2013. Essential Oil Composition of Ginger (Zingiber officinale Roscoe) Rhizomes from Different Place in India. Journal of Essential Oil Bearing Plants, 8(2): 187-191.

Sasidharan, I., V.V. Venugopal and A. Nirmala Menon., 2011. Essential oil composition of two unique ginger (Zingiber officinale Roscoe) cultivars from Sikkim. Natural Product Research, 26(19): 1759-1764.

Singh, G., I.S. Kapoor, P. Singh, C.S. Heluani, M.P. Lampasona and C.A.N. Catalan., 2008. Chemistry, antioxidant and antimicrobial investigation on essential oil and oleoresine of Zingiber officinale. Food and Chemical Toxicology, 46(10): 32953302.

Stoyanova, A., A. Konakchiev, S. Damyanova, I. Stoilova and P.T. Suu., 2013. Composition and Antimicrobial Activity of Ginger Essential Oil from Vietnam. Journal of Essential Oil Bearing Plants, 9(1): 93-98.

VandenBerghe, D.A. and A.J. Vlietinck., 1991. Screening Methods for Antibacterial Agents from Higher Plants. In: Dey, P.M., Harborne, J.B. and Hostettman, K., Eds., Methods in Plant Biochemistry, Assay for Bioactivity, Vol. 6. Academic Press, London, 47-69.

Verma, RS., R.K. Verma, A. Chauhan and A.K. Yadav., 2009. Changes in the essential oil content and composition of Eucalyptus citriodora Hook during leaf ontogeny and leaf storage. Indian Perfumer, 53: 22-25. 